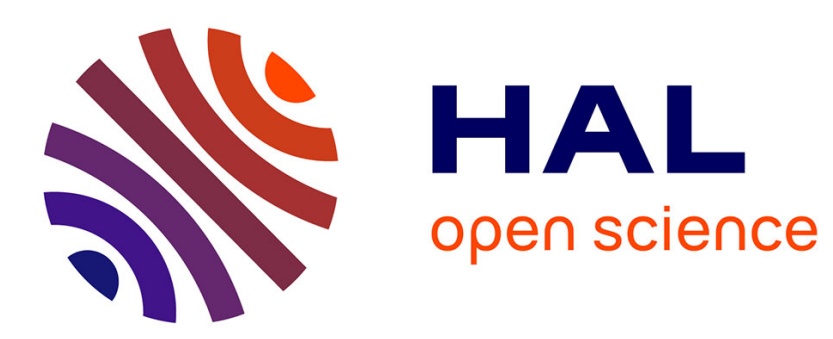

\title{
Ritual and Social Evolution: Understanding Social Complexity Through Data
}

Harvey Whitehouse

\section{To cite this version:}

Harvey Whitehouse. Ritual and Social Evolution: Understanding Social Complexity Through Data. 2nd International Workshop on Computational History and Data-Driven Humanities (CHDDH), May 2016, Dublin, Ireland. pp.3-14, 10.1007/978-3-319-46224-0_1 . hal-01616304

\section{HAL Id: hal-01616304 https://hal.inria.fr/hal-01616304}

Submitted on 13 Oct 2017

HAL is a multi-disciplinary open access archive for the deposit and dissemination of scientific research documents, whether they are published or not. The documents may come from teaching and research institutions in France or abroad, or from public or private research centers.
L'archive ouverte pluridisciplinaire HAL, est destinée au dépôt et à la diffusion de documents scientifiques de niveau recherche, publiés ou non, émanant des établissements d'enseignement et de recherche français ou étrangers, des laboratoires publics ou privés. 


\title{
Ritual and social evolution: Understanding social complexity through data
}

\author{
Harvey Whitehouse \\ University of Oxford, UK
}

\begin{abstract}
This paper introduces a new a new database of world history known as 'Seshat' $[12,13]$. Seshat is the Egyptian deity of writing, knowledge and wisdom and her name literally translated means "she who scribes". It could be said that Seshat was the first goddess of databases and so we have borrowed her name for our global history databank. The aim here is to show how Seshat can be used to test theories about the evolution of social complexity. First we will consider how such theories can be inspired by qualitative observation of patterns in the social world. For the purposes of illustration we will consider the theory of "modes of religiosity". We will examine efforts to test this theory against data on real world groups, past and present. Finally we will consider how this theory can be tested in a more rigorous and systematic way using Seshat: Global History Databank.
\end{abstract}

\section{Introducing Seshat}

Much is known about past societies but it is all scattered" and unavailable in its current form in texts and the minds of many thousands of historians and archaeologists and cannot be readily analysed using statistical tools. Even historical materials stored electronically are not organized in a way that can be used to test theories. Seshat will allow us to connect facts about the past spatially, temporally, thematically, and conceptually. We will be able to use Seshat to test theories about cultural evolution, discarding those that turn out to be false. At the same time we can use Seshat to analyse patterns within societies (e.g. looking at how social complexity compares with variables on ritual and warfare) as well as across them.

Eventually we want Seshat to contain extensive data on every single society ever documented on the face of the earth. But we must be realistic and so our initial goal is to sample past societies selectively. We have chosen thirty regions spread around the world to serve as a sampling scheme and for each of these regions we capture details of polities that rose and fell between the Neolithic and industrial revolution. "World Sample 30" as it has become known was created by first dividing the world into ten major regions and then choosing three "Natural Geographic Areas" (NGAs) from each of them. Each NGA represents an area with some ecological unity, roughly $100 \mathrm{~km} \times 100 \mathrm{~km}$ in size (although NGAs can be somewhat larger or smaller than that). The three NGAs selected for each world region are ones that developed social complexity very early (like Upper 
Egypt), very late (like Iceland) or somewhere in the middle (like Chuuk). The purpose of stratifying the sample in this way is to maximize variance in the data. But obviously this is all relative - so the most complex NGA in OceaniaAustralia is Big Island Hawaii which is nothing like as complex as (say) Latium. For each NGA we code data pertaining to polities (e.g. states like Egypt's classic old kingdom) or quasi-polities (e.g. sub-traditions) as far back as the data will allow. This means for some NGAs we only have a few time slices whereas for Upper Egypt we have about 40 or so.

The process of populating the database involves a well-established division of labour. RAs code the data initially and then gather expert input. The data aren't static - new insights be incorporated. In other words we do not freeze data or its interpretation forever. We also capture uncertainty and disagreement - we do not want to 'paper over' these crucial aspects of humanities research. Each item of information coded in Seshat is not a simple datapoint. Even seemingly simple facts like the size of the largest settlement in Egypt's New Kingdom Ramasside period (to take a simple example) is actually a conglomerate of information with a complex structure. We can handle uncertainty by including population ranges and other estimates (we never try to go beyond what the current state of knowledge allows). Each piece of information is linked by a numbered footnote to a source. This information is vetted by experts - and every time it is updated or changed this action is recorded.

\section{The theory of modes of religiosity}

Seshat has been designed to test theories about the evolution of social complexity (http://seshatdatabank.info). But where do such theories come from in the first place? Here we consider the example of one such theory, concerning modes of religiosity (or simply the 'modes theory'). The modes theory predicts that collective rituals tend to fall into two main types: doctrinal and imagistic [14, $15,16]$.

A hallmark feature of the doctrinal mode of religiosity is that the main teachings and practices are frequently repeated. Think for example of Sunday Church services or Friday prayers at the Mosque). These kinds of routinized rituals are typically accompanied by sermonizing, in which narratives and creeds are repeatedly rehearsed and memorized. So it is easy to spot unauthorized innovations so as to produce a stable and shared body of doctrine. Doctrinal practices tend to spread rapidly and become standardized across much larger populations. Religious hierarchies typically become established enforcing the orthodoxy and punishing heresy. The frequent repetition of doctrinal rituals - from daily prayers to weekly Holy Days through to all the events that fill up religious calendars - serve to cement the social identity of potentially enormous social groups, sometimes even on a global scale.

The imagistic mode, on the other hand, is based around rarely performed rituals involving much higher levels of emotional intensity (e.g. painful initiation rituals or gruelling tests of stamina and self-deprivation). These ritualized 
ordeals trigger personal reflection on the meaning and symbolism of the acts and artefacts involved, but are not necessarily linked to a religious orthodoxy of any kind. Imagistic practices are very effective at binding local networks of people into tightly knit, emotionally bonded communities. They seem to create a sense of family connection based, not on bonds of kinship and descent, but on the sharing of life-changing ritual experiences. On they other hand they don't spread very efficiently - passing on the tradition requires the entire ritual community to come together (unlike doctrinal practices that can be passed on by word of mouth or the spread of holy books). This means that imagistic groups tend to be localized and uncentralized. Now, underlying the two modes are two distinct ways of remembering.

In the case of the doctrinal mode, belonging to the community basically means sharing a set of group-defining beliefs and practices. These beliefs and practices will have been socially learned from other people in the group and many of them are regularly repeated and stored as part of the person's general knowledge about the world. Psychologists refer to this kind of knowledge as 'semantic memory' [11]. A good example is the general fact that Elisabeth II is the Queen of England. This is one of countless facts that every normal person in the UK, above a certain age, simply knows. Not knowing this kind of thing would arouse suspicions that the person in question is not 'one of us'.

A great deal of semantic knowledge consists of beliefs and behaviours that collectively - that is, taken together as an entire cultural system - demonstrate membership of the group. But cultural knowledge of this kind is also very impersonal. When information is stored in semantic memory it is more or less disconnected from time and space. For example, who can remember where or when they first learned who is currently the queen of England? It is just something we know - and although there must have been a time when that information was new to us, these personally salient details have typically fallen away; it is just a generic fact rather than a part of our personal, lived experience. Moreover, it is impersonal in another way as well - most of the content of semantic memory is acquired from others via social learning. We had to be told that Elizabeth II is the queen of England; it is not a conclusion we reached through some independent process of discover.

Doctrinal religions basically consist of beliefs and practices that are stored in semantic memory [16]. We can think of a religious orthodoxy as a great corpus of things you are supposed to do and say in order to be an upstanding member of the religious community. But because of the way these beliefs and practices are processed in memory, they are essentially also impersonal. When our religious identities are made salient our personal selves become less so, and vice-versa. Group psychologists refer to this as 'identification' $[6,10]$ - and over several decades the field of 'Social Identity Theory' suggests that this form of group alignment is essentially depersonalizing. When our semantic memory for groupdefining beliefs is activated we are less conscious of our own personal identities.

In the case of imagistic practices, group alignment comes about in a very different way from a cognitive perspective. In particular, the types of memories 
that matter are firmly rooted in one's personal life history. Psychologists refer to these as 'episodic memories' because they specify the details of a particular moment or sequence of events in lived experience [11]. Some of these memories are so emotionally intense, unique, and consequential that we can never forget them. Typically, the most long-lived of these memories are for dysphoric experiences - such as painful or frightening episodes [3]. These rare but very intense experiences shape the personal self - we call them 'transformative' or 'self-shaping' episodes [8]. In the case of dysphoric rituals, such as painful initiations, these can trigger a great deal of reflection on their significance and meaning. And when such experiences are felt to be shared with other members of the group this produces a visceral sense of oneness, known as identity fusion $[9,4]$.

Identity fusion is unlike identification in that it taps directly into the personal self. In the case of the doctrinal mode, making the group salient makes the personal self less so - but it's quite the opposite with the imagistic mode. People who have shared the same self-shaping experiences regard the group and the self as functionally equivalent - if you make the group salient you activate the personal self-concept and vice-versa. So the idea here is that imagistic rituals fuse participants to the group - creating in effect an extremely powerful form of social cohesion capable of motivating quite extreme forms of pro-group action, including willingness to fight and die for the group.

For some years now we have been studying the psychological effects of these two kinds of group bonding - doctrinal and imagistic - in a wide range of cultural groups. As well as studying religious adherents, we have also been studying a much wider range of groups: football fans, soldiers, university fraternities, revolutionaries, and tribal warriors [21, 18]. And we find the same pattern in all these different contexts: high-frequency/low arousal rituals give rise to identification and other doctrinal features; low-frequency/high arousal rituals give rise to fusion and other imagistic features [20].

\section{Modes of Religiosity over Time and Space}

Modes of religiosity are manifested in bounded regions during relatively discrete time periods - and so if we want to observe how they wax and wane we need to study the histories of various groups. This is something scholars have been doing for some time $[22,7,5]$. An instructive example is the way historian Anne Clark has discussed evidence of modes dynamics in late medieval English monasteries $[2]$.

On the one hand, Clark found extensive evidence for the doctrinal mode of religiosity: routinized transmission, heavy emphasis on verbal and textual codification of a religious orthodoxy, coupled with expansionary, centralizing, and hierarchical dynamics. But on the other hand, Clark also pointed to evidence of monastic practices that had a more imagistic character, for example in the form of visions and other extraordinary interactions with the divine. Although rare in the lifetimes of individuals such experiences were widespread aspects of religious life. But unlike truly imagistic practices, the visions and visitations 
Clark described in the monasteries tended to be uniquely personal and solitary rather than part of any kind of collective ritual. As such these experiences were incapable of generating the distinctive patterns of localised group alignment and cohesion diagnostic of the imagistic mode.

Clark's careful descriptions of medieval religious practices provided new insights into the way doctrinal religions can co-opt certain kinds of personal experience in building commitment to mainstream beliefs and practices. Case studies like these have undoubtedly been valuable not only in exploring the applicability of the modes theory to historical materials but in extending the reach of the theory to consider a diversity of ways in which doctrinal and imagistic dynamics have had to adapt to the conditions typical of different regions and historical periods.

Nevertheless, an obvious problem with these kinds of case studies is that of self-selection: were cases studies more likely to be chosen because they supported the modes theory? Note that bias of this kind does not even need to be deliberate. Perhaps some scholars were interested in the theory because it resonated with their data, maybe prompting questions and criticisms as well as confirmatory evidence, but in a way that nevertheless skewed the sample of available case studies to favour the theory. Perhaps other historians would regard the doctrinal/ imagistic distinction to be simply irrelevant to the groups they know about, or just plain wrong? To avoid the charge of cherry-picking case studies that fit the theory, we needed a more objective way of testing our hypotheses using a much larger sample. Consequently we decided to build a cross-cultural database on rituals using material extracted from a vast electronic storehouse of ethnographic writings known as the Human Relations Area Files [1].

Over several years we compiled data on 645 rituals from 74 cultures around the world. For each of the rituals in our database we coded for approximately 100 variables, including estimated performance frequencies, indicators of emotional intensity (both euphoric and dysphoric), and a wide range of measures of social cohesion, group organization, scale, complexity, and agricultural intensity. Having such a massive volume of information coded in this way enabled us to look for correlations among our variables of interest - allowing us to test the principal predictions of the modes theory. Fig. 1 shows that the performance frequency of rituals in our database (the blue line in the graph, bottom right) correlated negatively with dysphoric arousal. Moreover there was a clear bunching of rituals around the low-frequency/dysphoric end of the spectrum and the high-frequency/low-arousal end (shown as red cells in the 'heat map' top left). Interestingly, the relationship between frequency and euphoria (the green line in the graph, bottom right - and heat map top right) was more of a U-shaped curve, with the most euphoric rituals peaking around annual frequency.

Establishing an inverse relationship between ritual frequency and dysphoria was extremely important to us because this was one of the central predictions of the modes theory. The initial phase of analysis was a nail-biting exercise because of course our predictions could have proven to be completely wrong - it could quite easily have been the case, for example, that the most painful 
or frightening rituals occur seasonally or annually. We went on to show that dysphoric rituals are correlated with many of the other diagnostic features of the imagistic mode whereas high-frequency rituals are correlated with those of the doctrinal mode. And we also discovered something else that turned out to be important archaeologically - namely that as rituals become more frequent and less dysphoric, agricultural intensity increases. This pointed to the possibility that the transition from foraging to farming in the early Neolithic may have been linked to the rise of the doctrinal mode.

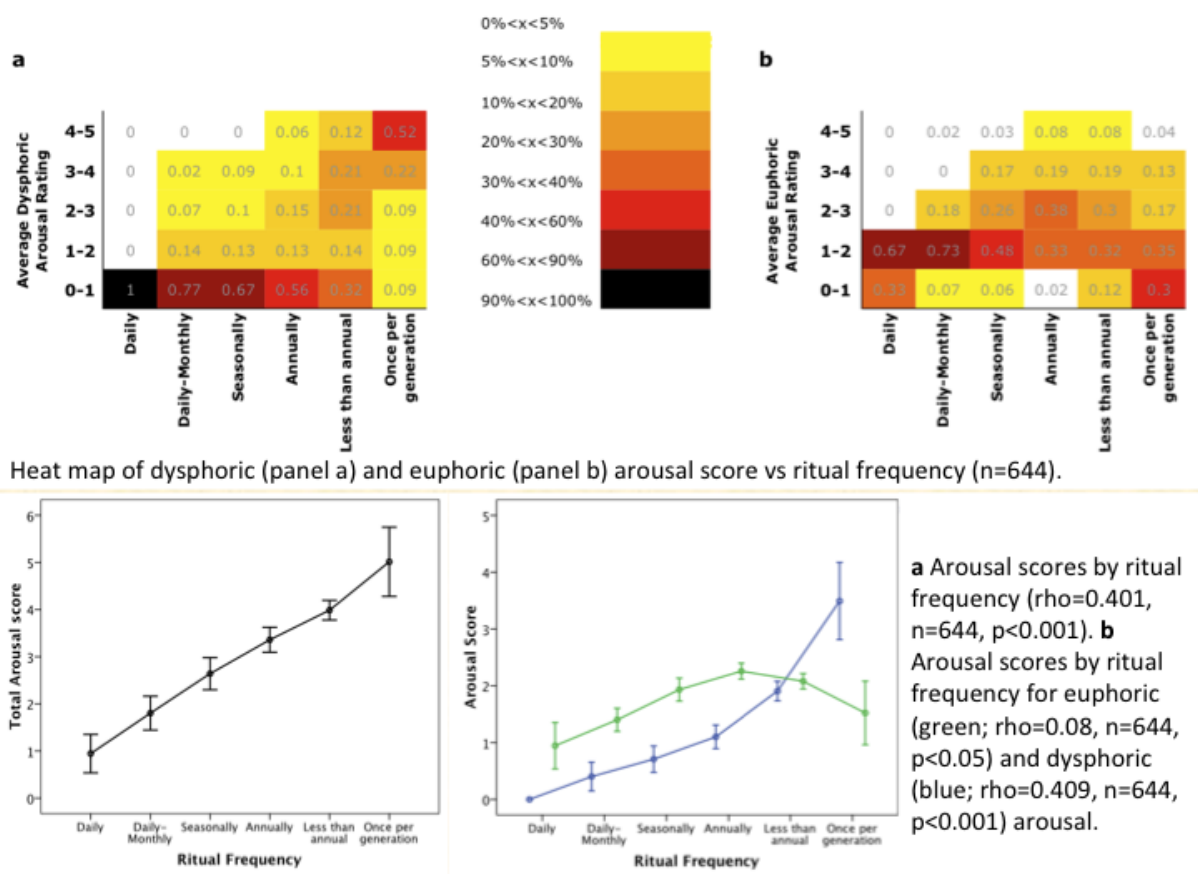

Fig. 1. Frequency and arousal in a sample of 644 rituals from 74 cultures (reproduced from [1])

In an effort to find out whether a basic shift from imagistic to doctrinal dynamics did indeed feature in rise of agriculture and the evolution of social complexity, I went to atalhyk in Turkey, the site of an ancient civilization that flourished during the period of transition from hunting and gathering to settled farming, but still long before the first agrarian states emerged. I ended up returning to atalhyk many times, as part of what became a long-term collaboration with the director of the site, Ian Hodder [19, 23].

atalhyk was a large, densely populated settlement established around nineand-a-half thousand years ago and lasting for nearly two millennia. At atalhyk we 
have found evidence of a gradual shift from the imagistic practices of small group living to much larger-scale group bonding based on higher-frequency doctrinal rituals. Some of our evidence for this shift comes from pictorial representations of imagistic practices in the early phases of settlement - for example, paintings that show the teasing and baiting of bulls, deer, bear, and boar by crowds of participants and depicting what look like rattles and drums as well as dancing figures. The animals in these paintings would have presented a grave threat to human life and limb. Wild cattle at atalhyk were much larger than their domesticated descendants - adult bulls standing two metres in height at the haunches. Faunal remains at the site show that these animals were slaughtered at large feasting events. We know from the nature of these deposits that feasting rituals occurred sporadically, perhaps once or twice in a generation, consistent with imagistic dynamics. Moreover, the rituals associated with the closure and rebuilding of houses occurred every 70-100 years on average and seemed to elicit strong emotions associated with the handling of human remains.

One of the many clues to the imagistic character of early ritual life at atalhyk is the pervasive emphasis on hiding and revealing, on what Hodder and I have called 'revelatory' practices. Obsidian hoards were placed beneath floors and periodically retrieved. Paintings were repeatedly remade and then covered over. Claws of bears, teeth of foxes and weasels, tusks of wild boars, and beaks of vultures were being placed in walls, repeatedly extracted, replaced, and then covered over. Bucrania were installed in walls and on upright posts. Human skulls and body parts were continually being removed from the floors of domestic dwellings and then reburied and the hiding and revealing of body parts showed remarkably detailed and durable memory for burial locations.

Roughly halfway through the period of settlement at atalhyk the ritual life seemed to change, however. Evidence of the hunting-feasting complex fade and it seems as if imagistic practices are being progressively replaced by a more doctrinally codified belief system, stewarded by orators and expert cosmologists. Hodder and I found many indicators of a more 'discursive' style of religiosity, for example manifested in the designs of stamp seals, paintings, and narrative transmission in what we came to describe as 'history houses'. We saw evidence of increasing standardization of group ideology in the recurring themes of acts and artefacts and especially the way pottery and obsidian production becomes more homogeneous and centralized. We think the emergence of the doctrinal mode at atalhyk constituted a milestone in the evolution of human civilizations, paving the way for more centralized, large scale, and hierarchical patterns of political association. Much previous theory had proposed that this step forward in political evolution was rooted in changing technology and modes of production. But Hodder and I have argued, by contrast, that larger-scale, centralized patterns of social organization were triggered by a shift in people's ritual lives, beginning somewhat earlier than is generally supposed.

One of the ways we have tried to test this hypothesis is by building longitudinal databases. The excavations at atalhyk have so far produced more than 50,000 units of archaeological material, each carefully catalogued in a massive 
electronic store. We began by recoding selected portions of this material in our own database to include proxies for social complexity, agricultural intensity, and the frequency, scale, and emotionality of ritual performances. This in itself was a major operation and of course raised many challenges of archaeological interpretation. But when we finally came to analyse the data a strong overall picture emerged.

What we found was that rare, emotionally intense, communal rituals decline over the period of settlement and are replaced by more routine family-based rituals. We also saw a shift away from elaborate symbolism and imagery towards more discursive practices associated with mobile objects with standardized designs. These findings were consistent with the view that imagistic practices progressively gave way to more doctrinal ones. We also found a striking correlation between the rise of the doctrinal mode and levels of agricultural intensity. A less welcome discovery, from the perspective of our theoretical framework, was that these processes did not correspond to a growth in the size and density of the population. Actually, we found the reverse - the settlement became smaller and more dispersed. What we think may have happened is that as the doctrinal mode emerged, households became more independent of the communal band and more diffuse ethnic identities encompassing larger and more dispersed populations took over from the local cult group bonded through imagistic practices. Paradoxically, as settlements thinned out and dispersed, social identities may have been greatly expanded - uniting much larger populations.

To test that hypothesis we needed to go beyond atalhyk and examine trends in the changing character of ritual and social morphology over a wider area and over a much longer period of time. For the past three years we have been building a regional database covering nearly all the archaeological sites of Anatolia and the Levant from the end of the Paleolithic to the beginning of the Bronze Age. This has been a labour intensive process involving a larger team but we have now begun to analyse the results. The overall picture that's emerging seems to be consistent with our theory. In the earlier sites surveyed, ritual life bore all the hallmarks of the imagistic mode. Over time large-scale feasting declines and instead a focus on secondary burial becomes a major focus of ritual life, a transformation that we think was linked with the emergence of much larger social groupings based on principles of clanship and descent.

The process of testing the modes theory using ethnographic and archaeological databases has taught us that the history of the mind is simultaneously both local and global and must be studied both qualitatively and quantitatively. One cannot fully understand one aspect in isolation from the other. If, for example, one were to try to understand the relationship between the frequency and emotional intensity of rituals - including their implications for cognitive processes like memory and group alignment - purely by doing qualitative historical research, the picture would be skewed and incomplete. It would be skewed because of the problem of self-selection. And the picture would be incomplete because certain important relationships, for example between ritual frequency and agricultural intensity, are only discoverable through statistical analysis of 
large samples. But by the same token, none of the quantifiable patterns we are interested in would have been discernible without detailed qualitative data.

\section{Using Seshat to Test the Modes Theory}

Seshat will allow us to go far beyond the methods and findings outlined above, to detect a vast range of patterns in the evolution of social complexity, including both short-term and localized trends in the history of the mind - and much longer-term changes across regions and continents. Among other things, Seshat will enable us to test the core predictions of the modes theory longitudinally on a global scale. So let's look at some specific examples of predictions, based on the modes theory, that Seshat will allow us to test, for the first time (for a fuller list, see [17]).

Our first prediction is that intensification of agriculture correlates with increasing routinization of ritual and the rise of orthopraxy. As we have seen, our surveys of ethnographic and archaeological materials suggest that agriculture leads to more frequent collective rituals. The rationale behind this prediction is that farming requires increasing reliance on regularized forms of cooperation including collective rituals. For this prediction, and in fact for all our predictions, we specify an alternative scenario that could, quite plausibly, turn out to be the case. In the case, the alternative might be that routinization and orthopraxy are triggered by factors unrelated to agriculture (e.g. warfare, trade, status inequality, the polarization of economic classes, etc.). So the idea is that we're really using the data to adjudicate between competing possibilities.

Following on from this, our second prediction is that routinized rituals gave rise to larger political units. It's a truism of social science research that rituals bolster the status quo but it is only possible for rituals to serve this function if they enshrine a set of features common to the political unit as a whole.

But in order for a set of beliefs and practices to become standardized across large populations, they need to be enacted with sufficient regularity that everyone remembers their content and meaning in more or less the same way. Repetitive rituals (e.g. conducted on a daily or weekly basis) allow a body of beliefs and practices to become fixed and standardized. We therefore predict the rise of ritual routinization prior to the appearance of large-scale political systems. The alternative of course is that it's the other way around - large-scale polities arose first and routinization came later. Seshat will allow us to find out which is the case.

A third prediction is that the rise of orthopraxy leads to more stable and long-lived civilizations. To the extent that routinization leads to the standardization of beliefs and practices and the emergence of centralized hierarchies, we'd expect the resulting orthopraxy to bolster the status quo and so contribute to the stability and endurance of the social order. Functionalist arguments of this kind once enjoyed almost hegemonic status in the social sciences. But they have been heavily criticised in recent decades mainly on the grounds that not all societies are functionally integrated and stable - and even if some are it is hard 
to explain how that functional integration came about. Some of these issues will be possible to address systematically for the first time using Seshat. Are certain features of rituals correlated with political stability over time, as we would predict? Are there conditions under which those same ritual features can become dysfunctional (leading to revolutions or failed states, for example)? The modes theory presents a series of sub-hypotheses regarding cyclical patterns of splintering and reformation in doctrinal religions - all of which can in principle be tested using the kind of longitudinal information that Seshat will provide.

Now, obviously, the process of testing hypotheses like these, using large historical databases, presents many challenges. The processes involved in converting raw data into something we can analyse statistically are extremely complex. The more complex a methodology becomes, of course, the greater the risk of things going wrong. And there are many other challenges and potential pitfalls to deal with as well. Attempting to calibrate the emotional intensity of rituals, for example, or the extent to which people in the past reflected on the meanings of their rituals, requires a lot of knowledge about historical contexts. Therefore, we need a system for capturing variables in ways that are highly sensitive to the nuances of particular contexts. But how can we be sure that this quality of 'being sensitive to nuances' will be equally achievable for different periods or regions of the world? How do we reduce the effects of ethnocentric bias, for example when constructing items for inclusion in our codebooks? How do we capture degrees of uncertainty about the data - or disagreement among different historians? How do we deal with differences of granularity of data, particularly as we go further back in time?

These problems aren't unique to those of us working with large databases. Actually conventional historical research faces many of the same challenges as a matter of course. In fact, whenever historians make comparisons across periods or regions they run into at least some of these issues. But the task of quantifying history arguably brings these problems into much sharper focus in part because of the scale and remoteness of comparisons. To be sure, comparing some aspect of late medieval and early modern England presents difficulties of cultural commensurability, bias, missing data, interpretive disagreement, and so on. But imagine how much more difficult those issues become when comparing the rituals of, say, Tudor London with those of, say, atalhyk.

We are not alone with these problems, however. In the future, hordes of scholars and scientists will no doubt take up where we will leave off. After 2025, Seshat will become open access. Researchers will be able to test more and more hypotheses about the dynamics of social and cultural evolution in far more detail than has been possible up till now. And there's an even grander hope at the core of this - a hope about harnessing this new kind of knowledge to improve the world around us. Many of us believe that we'll be able to use our new science of history to make societies in the future more humane - maybe even harnessing group alignments in ways that lead to more effective cooperation, and especially more peaceful forms of competition, in centuries and millennia to come. 
Acknowledgements This work was supported by a John Templeton Foundation grant to the Evolution Institute, entitled "Axial-Age Religions and the Z-Curve of Human Egalitarianism," a Tricoastal Foundation grant to the Evolution Institute, entitled "The Deep Roots of the Modern World: The Cultural Evolution of Economic Growth and Political Stability," an ESRC Large Grant to the University of Oxford, entitled "Ritual, Community, and Conflict" (REF RES060-25-0085), and a grant from the European Union Horizon 2020 research and innovation programme (grant agreement No 644055 [ALIGNED, www.alignedproject.eu]).

\section{References}

1. Atkinson, A. D. and Whitehouse, H. (2011). The cultural morphospace of ritual form; Examining modes of religiosity cross-culturally. Evolution and Human Behavior. Vol. 32, No.1: pp 50-62.

2. Clark, A. L. (2004) "Testing the Two Modes Theory: Christian Practice in the Later Middle Ages" in H. Whitehouse and L.H. Martin (eds.) Theorizing Religions Past: Archaeology, History, and Cognition, Walnut Creek, CA: AltaMira Press.

3. Conway, M. A. (1996). Autobiographical knowledge and autobiographical memories. In D. Rubin (Ed.), Remembering our Past. Studies in Autobiographical Memory (pp. 67-93). Cambridge/New York: Cambridge University Press.

4. Jimnez, J., Gmez, ., Buhrmester, M. D., Vzquez, A., Whitehouse, H. and Swann Jr, W. B. (2015). The Dynamic Identity Fusion Index (DIFI): A new continuous measure of identity fusion for Web-based questionnaires. Social Science Computer Review. DOI:10.1177/0894439314566178

5. Larson, J. (2016). Understand Greek Religion: A cognitive approach. London: Routledge.

6. Mael, F. and Ashforth, B. (1992) Alumni and their alma maters: A partial test of the reformulated model of organizational identification. Journal of Organizational Behavior,13, 103-123.

7. Martin, L.H., Pachis, P. (eds.) (2009). Graeco-Roman Religions and the Cognitive Science of Religion. In Imagistic Traditions in the Graeco-Roman World, Thessaloniki: Vanias.

8. Singer, J.A. and Salovey, P. (1993). The Remembered Self: Emotion and memory in personality. New York: The Free Press.

9. Swann, W. B., Jensen, J., Gmez, ., Whitehouse, H. and Bastian, B. (2012). When Group Membership Gets Personal: A theory of identity fusion. Psychological Review, Vol. 119, No. 3, pp 441-456.

10. Tajfel, H. and Turner, J. C. (1985). 'The social identity theory of intergroup behavior'. In: Worchel, S. and Austin, W. G. (Eds) Psychology of Intergroup Relations, 2nd edn, Nelson-Hall, Chicago.

11. Tulving, E. (1983). Elements of Episodic Memory. Oxford: Clarendon Press.

12. Turchin, P., Whitehouse, H., Franois, P., Slingerland, E. and Collard, M. (2012). A Historical Database of Sociocultural Evolution. Cliodynamics, Vol. 3, No. 2: pp 271-293.

13. Turchin, P., Brennan, R., Currie, T. E., Feeney, K. C., Franois, P., Hoyer, D., Manning, J. G., Marciniak, A., Mullins, D., Palmisano, A., Peregrine, P., Turner, E. A. L. and Whitehouse, H. (2015). Seshat: The Global History Databank. Cliodynamics: The Journal of Quantitative History and Cultural Evolution 6(1): 77-107. 
14. Whitehouse, H. (1995). Inside the Cult: religious innovation and transmission in Papua New Guinea, Oxford: Oxford University Press.

15. Whitehouse, H. (2000). Arguments and Icons: divergent modes of religiosity, Oxford: Oxford University Press.

16. Whitehouse, H. (2004). Modes of Religiosity: a cognitive theory of religious transmission, Walnut Creek, CA: AltaMira Press.

17. Whitehouse, H., Franois, P. and Turchin, P. (2015). The Role of Ritual in the Evolution of Social Complexity: Five predictions and a drum roll. Cliodynamics 6(2): 199-210. http://escholarship.org/uc/item/4836f93g

18. Whitehouse, H., Jong, J., Buhrmester, M. D., Gmez, ., Bastian, B., Kavanagh, C. M., Newson, M., Matthews, M., Lanman, J. A. and Gavrilets, S. (Under Review). The evolution of extreme cooperation via intense shared experiences. PLoS Biology.

19. Whitehouse, H. and Hodder, I. (2010). Modes of Religiosity at atalhyk. In Hodder, I. (ed.) Religion in the Emergence of Civilization: atalhyk as a case study, Cambridge: Cambridge University Press.

20. Whitehouse, H. and Lanman, J. A. (2014). The Ties that Bind Us: Ritual, fusion, and identification. Current Anthropology, Vol. 55, No.6.

21. Whitehouse, H., McQuinn, B., Buhrmester, M. and Swann, W. B. (2014). Brothers in Arms: Libyan revolutionaries bond like Family. Proceedings of the National Academy of Sciences. Vol 111, No. 50: pp 17783-17785.

22. Whitehouse, H. and Martin, L. H. (eds.) (2004). Theorizing Religions Past: Archaeology, History, and Cognition, Walnut Creek, CA: AltaMira Press.

23. Whitehouse, H, Mazzucato, C., Hodder, I. and Atkinson, Q. D. (2013). Modes of religiosity and the evolution of social complexity at atalhyk. In Hodder, I. (ed.) Religion at Work in a Neolithic Society: Vital Matters. Cambridge: CUP. 